\title{
Enolases - storage compounds in seeds? Evidence from a proteomic comparison of zygotic and somatic embryos of \\ Cyclamen persicum Mill.
}

Christina Rode ${ }^{1 凶}$, Sébastien Gallien ${ }^{2}$, Dimitri Heintz ${ }^{3}$, Alain Van Dorsselaer ${ }^{2}$, Hans-Peter Braun $^{1}$, and Traud Winkelmann ${ }^{4}$

${ }^{1}$ Institute of Plant Genetics, Leibniz Universitaet Hannover, Herrenhaeuser Str. 2, D-30419 Hannover, Germany

${ }^{2}$ Laboratoire de Spectrométrie de Masse Bio-Organique, IPHC-DSA, Université de Strasbourg, CNRS, UMR7178; 25 rue Becquerel, F-67087 Strasbourg, France

${ }^{3}$ Institut de Biologie Moléculaire des Plantes (IBMP) CNRS-UPR2357, Université de Strasbourg, F-67083 Strasbourg, France

${ }^{4}$ Institute of Floriculture and Woody Plant Science, Leibniz Universitaet Hannover, Herrenhaeuser Str. 2, D-30419 Hannover, Germany

${ }^{凶}$ rode@genetik.uni-hannover.de

Phone: +049 5117623264

Fax: +0495117623608

\section{Keywords}

Differential gel electrophoresis, Embryogenesis, Mass spectrometry, Proteome reference maps, Protein identification, Two-dimensional polyacrylamide gel electrophoresis 


\section{Abbreviations}

AA: Amino Acids, CBB-G 2502D: Two-dimensional, 2iP: 6-(c,cdimethylallylamino)purine, 2,4-D: 2,4-dichlorophenoxyacetic acid, DIGE: Differential gel electrophoresis, EST: Expressed sequence tag, GAPDH: Glyceraldehyde-3-phosphate dehydrogenase, Glu: Glutamine, His: Histidine, HSP: heat shock protein, IEF-SDS PAGE: Isoelectric focusing Sodium dodecyl sulphate Polyacrylamide gel electrophoresis, LC: Liquid chromatography, Lys: Lysine, MS: Mass spectrometry, SE: Somatic embryos, Ser: Serine, TCA: Tricarbonic acid cycle, ZE: Zygotic embryos

\section{Abstract}

Somatic embryogenesis is well established for the economic relevant ornamental crop Cyclamen and thus could supplement the elaborate propagation via seeds. However, the use of somatic embryogenesis for commercial large scale propagation is still limited due to physiological disorders and asynchronous development within emerged embryos. To overcome these problems, profound knowledge of the physiological processes in Cyclamen embryogenesis is essential. Thus, the proteomes of somatic and zygotic embryos were characterised in a comparative approach. Protein separation via two dimensional IEF-SDS PAGE led to a resolution of more than 1000 protein spots/gel. Overall, 246 proteins were of differential abundance in the two tissues compared. Mass spectrometry analysis of the 300 most abundant protein spots resulted in the identification of 247 proteins, which represent 90 distinct protein species. Fifty-five percent of the 247 proteins belong to only three physiological categories: glycolysis, protein folding and stress response. The latter physiological process was especially predominant in the somatic embryos. Remarkably, the glycolytic enzyme enolase was the protein most frequently detected and thus is supposed to play an important role in Cyclamen embryogenesis. Data are presented that indicate involvement of "small enolases" as storage proteins in Cyclamen. A digital reference map was 
established via a novel software tool for the web-based presentation of proteome data linked to KEGG and ExPasy protein-databases and both were made publicly available online.

\section{Introduction}

Embryogenesis is a complicated process but, can be artificially induced from somatic tissues of some plant species. During somatic embryogenesis, cells develop completely outside the maternal context into normal embryos and further into whole morphologically intact plants (for review, see Zimmerman 1993). Somatic embryos resemble their zygotic counterparts morphologically in that they develop a bipolar structure and typical embryonic organs. Thus, somatic embryos can contribute to both basic research of embryogenesis due to easy researcher accessibility as well as to commercial high throughput plant propagation systems. The first report on plant somatic embryogenesis pertained to carrots and was published in 1958 (Steward et al. 1958; Reinert 1958). Currently, this plant is an established model for somatic embryogenesis research. Commercial multiplication of high-value clones via somatic embryogenesis has been realised for the forestry conifers Picea and Pinus by specialised nurseries (e.g., CellFor, Vancouver, Canada; Carter Holt Harvey Limited, Auckland, Australia).

Cyclamen persicum is a popular generatively propagated ornamental crop with high economic relevance. However, seed production is still cost intensive due to manual work as well as inbreeding depression of parental lines. Somatic embryogenesis has been shown to be an alternative propagation system in Cyclamen (Wicart et al. 1984; Kiviharju et al. 1992; Schwenkel and Winkelmann 1998). The production of embryogenic calluses and induction of embryogenesis is well established for cultivars (Winkelmann and Serek 2005) and wild species (Prange et al. 2010a, b). However, subsequent processes leading to physiological disorders, asynchronous development and misshaping in a relevant portion of emerged embryos are still not fully understood and thus hardly controllable. Consequently, in order to 
establish somatic embryogenesis as a standard technique in commercial Cyclamen propagation, it is of essential importance to elucidate the physiological processes within this specific developmental pathway.

Proteomic studies have been shown to be a powerful tool for monitoring the present physiological status of cells and tissues under specific developmental conditions (Rose et al. 2004). Initial analyses comparing the proteomes of somatic and zygotic embryos have been previously performed (Winkelmann et al., 2006), resolving over 200 protein spots per gel. More recently, Bian et al. (2009) analysed the proteomes of somatic embryos, zygotic embryos and non-embryogenic calluses of $C$. persicum and were able to identify 10 proteins. Using a comprehensive 2DE-DIGE approach, Lyngved et al. (2008) analysed embryogenic and non-embryogenic calluses of $C$. persicum. Data published on these initial studies provided important insights into Cyclamen embryogenesis. However, a large scale proteomic approach to characterise the proteomes of zygotic and somatic embryos in Cyclamen is still missing. We presume that the zygotic embryos have "optimal" protein composition, whereas in their somatic counterparts, some specific pathways may be underrepresented or missing.

Proteins related to seed development and storage compound accumulation are of special interest due to their impact on maturation and dormancy. These processes are less developed in the somatic embryos of Cyclamen compared with zygotic embryos, but required for a more uniform development and desirable long term conservation. Cyclamen seeds accumulate all three categories of energy rich molecules: starch, fatty acids and proteins in comparable ratios (Reinhardt 2006). Winkelmann et al. (2006) reported proteins involved in xyloglucan synthesis, rare storage carbohydrates, and globulins to be highly abundant in Cyclamen seeds. It is assumed, that working with a non-model organism like Cyclamen could result in identification of novel storage compounds. Those should not necessarily occur in form of new molecules but also alternative functions or modified forms of well known proteins are 
cogitable. Several storage proteins evolved from catalytic enzymes and still share sequence homologies and partly express metabolic functions (for review see Shewry 2003). For instance, patatin, the major storage protein in potato tubers, is closely related to acylhydrolases and esterases (Galliard, 1971; Hirschberg et al. 2001). Furthermore, also structural proteins occur in high concentrations in plant cells without adverse effects on the metabolic processes. Enolase, known as the $9^{\text {th }}$ glycolytic enzyme catalysing the reversible conversion of 2-phospho-D-glycerate to phosphoenolpyruvate (PEP) (Wold and Ballou 1957; Van der Straeten et al. 1991) has been shown to be encoded by a gene resembling genes for $\tau$ crystalin, a structural component in the eye lens of vertebrates (Wistow et al. 1988). In this study we will show, that modified forms of enolases may have lost their catalytic character and function as storage proteins in Cyclamen embryos.

We have chosen a comprehensive proteomic approach to systematically analyse the soluble protein sets found in both tissues. Proteins specific for each tissue were characterised to determine major differences. Information presented in this study could be of great importance for understanding embryogenesis in Cyclamen as well as optimising the production system of somatic embryos in vitro. A digital reference map was established and is publicly available via a novel software tool for the web-based presentation of proteome data. 


\section{Materials and methods}

\section{Plant material}

Zygotic and somatic embryos of the $C$. persicum commercial $F_{1}$ cultivar 'Maxora Light Purple' bred by the company Varinova (Berkel en Rodenrijs, Netherlands) were harvested at the torpedo stage. For this approach, zygotic embryos were prepared from seeds under a stereomicroscope (Zeiss, Jena, Germany) 11 weeks after self-pollination (Fig 1a). Embryos injured during the preparation were discarded. Somatic embryos were produced from embryogenic suspension cultures grown in half-strength liquid Murashige and Skoog (1962) medium, containing FeEDTA at full strength and $30 \mathrm{~g} \mathrm{l}^{-1}$ sucrose, $2 \mathrm{~g}^{-1}$ glucose, $9.05 \mu \mathrm{M}$ 2,4-D and $3.94 \mu \mathrm{M} 2 \mathrm{iP}$ as described by Winkelmann et al. (1998). For induction of embryogenesis, $1 \mathrm{ml}$ of a $500-1000 \mu \mathrm{m}$ cell fraction of the suspension adjusted to a density of $10 \%$ packed cell volume was plated onto plant growth regulator-free medium of the same basal composition $\left(20 \mathrm{ml}\right.$ in $9 \mathrm{~cm}$ petri dishes) solidified with $4 \mathrm{~g} \mathrm{l}^{-1}$ Gelrite (Duchefa, Haarlem, Netherlands). Medium and cells were separated by a disc of $100 \mu \mathrm{m}$ nylon mesh (Neolab, Heidelberg, Germany). After four weeks of incubation at $24^{\circ} \mathrm{C}$ in the dark, torpedoshaped embryos were harvested. Both tissues were frozen in liquid nitrogen directly after harvesting.

\section{Phenolic protein extraction and sample preparation for IEF}

Total proteins were extracted according to the protocol of Hurkman and Tanaka (1986) modified by Colditz et al. (2004). In brief: $80 \mathrm{mg}$ of plant material was pulverised in a bead mill and dissolved in lysis buffer (700 mM sucrose, $500 \mathrm{mM}$ Tris, $50 \mathrm{mM}$ EDTA, $100 \mathrm{mM}$ $\mathrm{KCl}, 2 \mathrm{mM}$ PMSF and $2 \%(\mathrm{v} / \mathrm{v}) \quad \beta$-mercaptoethanol, $\mathrm{pH}$ 8.0). After incubation and centrifugation, saturated phenol ( $\mathrm{pH}$ 6.6/7.9; Amresco, Solon, USA) was added and proteins were precipitated with $100 \mathrm{mM}$ ammonium acetate in methanol at $-20^{\circ} \mathrm{C}$ overnight. Proteins 
were pelleted and washed with $100 \mathrm{mM}$ ammonium acetate in methanol and with $80 \%$ acetone. Protein pellets were dried for a few minutes under a fume hood. Proteins were isolated in four independent extractions from four separate tissue fractions and each extraction was electrophoretically analysed by one gel replicate resulting in eight protein extractions and eight gels in total. Therefore, the protein pellet was resuspended in $350 \mu$ l rehydration buffer (8 M urea, 2\% [w/v] CHAPS, 100 mM DTT, 0.5\% v/v IPG-buffer [pH 3-11 non linear, GE Healthcare, Freiburg, Germany] and a trace of bromophenol blue). For one additional protein extraction resulting in one gel, Complete Mini protease inhibitor cocktail (Roche, Mannheim, Germany) was added to all buffers.

\section{D IEF/SDS-PAGE and protein staining}

For first dimension isoelectric focussing, complete protein fractions extracted from $80 \mathrm{mg}$ of fresh embryo tissue resuspended in $350 \mu$ rehydration buffer were loaded on Immobiline ${ }^{\mathrm{TM}}$ DryStrip gels $(18 \mathrm{~cm}, \mathrm{pH}$ gradient [pH 3-11, non-linear] (GE Healthcare, Freiburg, Germany)), overlaid with mineral oil and isoelectrically focussed for $24 \mathrm{~h}$ with voltages from 30 to $8000 \mathrm{~V}$ at maximum according to Mihr and Braun (2003) using the IPGphor system (GE Healthcare, Freiburg, Germany). For second dimension separation (SDS PAGE), focussed IPG strips were incubated two times for 15 minutes in equilibration solution (50 mM Tris- $\mathrm{HCl}[\mathrm{pH} 8.8], 6 \mathrm{M}$ urea, 30\% [v/v] glycerin, 2\% [w/v] SDS) supplemented first with 1\% $(\mathrm{w} / \mathrm{v})$ DTT and second with $2.5 \%(\mathrm{w} / \mathrm{v})$ iodoacetamide. Gel strips were placed horizontally on a 12\% Tricine SDS-PAGE gel. A Broad Range Protein Molecular Weight Marker (10-225 $\mathrm{kDa}$, Promega, Madison, USA) was used as molecular mass standard in the second dimension. Electrophoresis was carried out for $20 \mathrm{~h}$ at $30 \mathrm{~mA} \mathrm{~mm}^{-1}$ gel layer using the Biorad Protean IIXL gel system (Biorad, Muenchen, Germany). For Coomassie staining, proteins were fixed using $40 \% \mathrm{v} / \mathrm{v}$ methanol, $10 \% \mathrm{v} / \mathrm{v}$ acetate for at least $2 \mathrm{~h}$ and then stained 
overnight with colloidal Coomassie Blue CBB-250 G (Merck, Darmstadt, Germany) (Neuhoff et al. 1985,1990$)$.

\section{D gel analyses}

Gels were scanned and analysed using Delta 2D version 4.0 software (Decodon, Greifswald, Germany). Spot detection was achieved automatically and occasionally corrected by hand. For determination of significant alterations in the spot patterns of zygotic and somatic embryo proteomes, a Student's t-test was performed (confidence interval $>/=95 \%$ ) based on the relative spot volume. Thus, at least 1.5 fold alterations in protein abundance among both analysed groups were considered to represent true differences in protein levels.

\section{D IEF/SDS-DIGE}

One-hundred micrograms protein of the zygotic embryos protein fraction and $100 \mu \mathrm{g}$ protein of the somatic embryos protein fraction to be compared were labelled with CyDye ${ }^{\mathrm{TM}}$ Fluors (GE Healthcare, Freiburg, Germany). Protein quantification was carried out using the 2D QuantKit following the manufacturers protocol (GE Healthcare). For this approach, protein samples were resuspended in a minimum volume of CyDye labelling-compatible lysis buffer (40 mM Tris- $\mathrm{HCl}, 8 \mathrm{M}$ urea, 4\% [w/v] CHAPS at $\mathrm{pH} 8.5$ ). The zygotic protein fraction was labelled with $\mathrm{Cy} 3$, the somatic protein fraction with Cy5. Subsequently, protein fractions were pooled, loaded on one immobiline dry strip gel within a total volume of $350 \mu 1$ rehydration buffer and separated via IEF-SDS PAGE as described above. Afterwards, 2D gels were scanned at dye specific wavelengths using Typhoon Trio Fluorescence Scanner (GE Healthcare) at 100 micron resolution and an overlay image was created using Quant version 5.2 analysis software (GE Healthcare, Freiburg, Germany). 


\section{Mass spectrometry analysis and physiological clustering of identified proteins}

In total 300 spots have been analysed by mass spectrometry. Therefore, 263 proteins, which were present in all four replicates of the zygotic embryos IEF-SDS PAGEs, were picked from one zygotic embryos IEF-SDS PAGE in order to establish this gel as a reference map. These 263 spots were also present in the somatic embryos IEF-SDS PAGES. Additionally, 37 protein spots were picked from the somatic embryos IEF-SDS PAGE. Those 37 protein spots were characteristic for the somatic embryos proteome and very low abundant in the zygotic embryos IEF-SDS PAGE.

Protein spots were isolated manually from 2D IEF-SDS gels using GelPal Protein Excision System (Genetix, Queensway, U.K). For each spot one disc of $1 \mathrm{~mm}$ diameter was picked from Coomassie stained gels. Digestion of protein spots within the gels and nano-LC-MS/MS (Agilent 1100 Series HPLC-Chip/MS system (Agilent Technologies, Palo Alto, USA)) coupled to an HCT Ultra ion trap (Bruker Daltonics, Bremen, Germany) analyses as well as protein database searches against Viridiplantae downloaded from http://www.ncbi.nlm.nih.gov/sites/entrez were performed in accordance to Fuehrs et al. (2009) but with modifications described in supplementary material (S1). Two protein spots (ID8764, ID853) were indentified by Bruker Daltonics (Bremen, Germany) using nano HPLC ESI MS/MS system according to the companies protocol. Proteins were identified using MASCOT search against NCBI database following the companies protocol. All identified proteins were clustered according to the KEGG PATHWAY Database (http://www.genome.jp/kegg/pathway.html) but protein information was manually adapted by the authors to assign all identified proteins to one of the following 11 groups named a-k. The categories cellular processes (d), environmental information processing (g) and genetic information processing (h) remained unchanged. KEGG's category metabolism was subdivided into (three parts: carbohydrate metabolism (a), energy metabolism (b) and other metabolic pathways (c) analogous to KEGG's subdivision of this category but upgrading each 
of these to a main category. The embryogenesis/ seed-relevant groups storage proteins (f), development (j) and protein processing (h) were added by the authors. Also proteins involved in transport (e) were sorted separately. The group $\mathrm{k}$ included all uncharacterised proteins. Each category was further subdivided into 1-5 subcategories according to physiological subprocesses.

\section{Digital reference map}

A software tool named GelMap was programmed as a server-side using PHP scripting language on a standard MySQL version 5.0 database code (Sun Microsystems, Santa Clara, USA) based on the style of SpotLink (Hajduch et al., 2005) but including additional functions and made publicly available at the website: http://www.genetik.unihannover.de/cyclamen.html (Username: "genetik"; Password: "g3n3t1k". The reference map and the software GelMap will become freely available at the time of publication, but are protected via password during the reviewing process.). For this, a jpg-version of a gel scan and a tab separated text document containing $\mathrm{x}$ and $\mathrm{y}$ coordinates of protein spots as well as spot specific information were uploaded to GelMap.

\section{Results}

\section{Preparation of zygotic and somatic embryos of Cyclamen persicum}

The aim of our study was to compare the proteomes of zygotic and somatic embryos of Cyclamen persicum and thus elucidate the physiological aspects of embryogenesis in this species. For this approach, it was essential to analyse zygotic and somatic embryos of equivalent developmental stages. Therefore, zygotic torpedo-shaped embryos were prepared from seeds 11 weeks after pollination (Fig. 1a). At this time, the endosperm had already become solid, but not reached the fully desiccated stage, facilitating easy embryo isolation. Embryo and endosperm were separated by the epidermis of the embryo, thereby avoiding 
endosperm contamination in the prepared sample. Somatic embryos (Fig. 1b) were harvested from petri dishes four weeks after embryo induction. This was the time point of maximal morphological similarity to their 11-week-old zygotic counterparts. However, zygotic embryos appeared more defined and homogeneous, while somatic embryos were frequently misshaped and swollen with partly reddish brown discoloration. Compared to zygotic embryos, their development was less synchronous. Nevertheless, about 60 well-shaped somatic embryos could be selected from one petri-dish. In total, more than 1000 embryos were harvested from both tissues, and proteins were then extracted from $80 \mathrm{mg}$ portions ( 240 embryos) and loaded completely onto gels.

\section{D analysis of total proteins from zygotic and somatic embryos}

Separation by 2D IEF-SDS polyacrylamide gel electrophoresis led to gels of high resolution, allowing detection of a total of 1013 spots. Representative gels for each tissue are shown in Figure 2a (A: zygotic embryo proteome and B: somatic embryo proteome). Six-hundred eighty-one of these spots could be detected in all analysed gels with a minimum spot volume of $0.005 \%$. Nevertheless, by visual analysis all spots present in the zygotic embryo proteomes also were found in the somatic embryo proteomes, although in clearly changed abundance. A total of 137 protein spots were at least 1.5 -fold higher in abundance in the zygotic embryo proteomes and a total of 109 protein spots were at least 1.5 -fold more abundant in the somatic embryo proteomes. Proteins differing in abundance were visualised by the calculation of an overlay gel using the Delta-2D software tool (Fig. 2a, part C). For improved visualisation of the different protein abundance when comparing the two proteomes, a differential twodimensional gel electrophoresis approach (2D-DIGE) was performed (Fig. 2b). The DIGE experiment confirmed the abundance alterations as revealed by the Delta-2D mediated analysis (Fig. 2a, part C). 


\section{MS-based protein identification and physiological classification}

In order to identify proteins, mass spectrometry analysis was carried out for a total of 300 highly abundant spots from both protein fractions. These analyses led to the identification of 247 protein spots representing an $83 \%$ identification rate. Detailed information on the statistical parameters for protein identification is given in the supplementary material (Table S2). Within all identified proteins, three protein groups were of predominant distribution: 42 spots were identified as heat shock proteins (HSP); 28 spots were identified as enolase and 20 spots were identified as glyceraldehyde-3-phosphate dehydrogenase (GAPDH). All identified proteins were grouped according to a modified KEGG PATHWAY Database classification in 11 groups (a-k; table S3). A notable result of this classification was the fact that $55 \%$ of all spots identified were placed in only three categories: glycolysis, protein folding and stress response. In total, 90 of the identified spots represented non-redundant proteins and 8480 of them were described for the first time in Cyclamen embryos (Table S3). Those six proteins which were identified in earlier studies by Winkelmann et al. (2006) and Bian et al. (2009) are indicated in Table S3).

To highlight major differences in the physiology of zygotic and somatic embryos, Table 1 displays proteins found in increased abundance in the zygotic or somatic embryo proteomes. Evaluation was based on the assumption, that proteins appearing on gels according to their theoretical MW likely represented biologically intact proteins, while those that exhibited a clearly smaller molecular mass might represent proteolytic break-down products. For this reason, these two protein groups were evaluated separately.

Identified proteins of increased abundance in the zygotic embryo proteomes are given in Table 1a. Within the group "MW in-gel according to theoretical MW", six of twelve proteins were involved in house-keeping processes. Three of them exhibited the second, third and fourth highest increase in relative abundance: succinate/malate-CoA-ligase, malatedehydrogenase and voltage dependent anion channel protein. An oxireductase (zinc-binding 
dehydrogenase family) exhibited the highest increase of relative spot volume. Three proteins were related to stress response (copper/zinc superoxide dismutase, thioredoxin peroxidase 1 and universal stress protein). Two proteins were involved in protein processing or folding (Ubiquitin and HSP 20), of which HSP 20 made up the most prominent spot volume.

Remarkably, within the eight proteins in the group "MW in gel lower than theoretical MW", four proteins (auxin-amidohydrolase, GDSL esterase/lipase, em-like protein and 7S globulin) that exhibited the highest increases in relative abundance were directly or indirectly related to seed development or storage compound physiology. Additionally, the spot identified as $7 \mathrm{~S}$ globulin was very prominently visualised on gel based on its spot volume.

In the somatic embryo proteomes (Table 1b), relative abundance were increased much higher in comparison to the zygotic embryo proteomes. Three out of the eighteen proteins had an increased relative abundance higher than 10 (19.9-10.6) and four proteins higher than 6.0 (7.7-6.0). By contrast, in the zygotic embryo proteomes, the highest increase in relative abundance value was 5.3.

Within the group "MW in-gel corresponding to theoretical MW" which included 15 proteins, the four most prominent ones were involved in stress response. While osmotin-like protein and antioxidant 1 exhibited the highest relative abundance, the catalase protein spot group appeared most visible in the upper gel region due to its horizontal chain-like arrangement. Proteins of primary metabolic processes were detected in similar abundance in the somatic embryo proteomes as compared to the zygotic embryo proteomes, representing the group of second highest increased abundance. An embryogenesis-specific LEA family protein was found in somatic embryos. HSP 60 was detected on the gel in a region corresponding to its theoretical MW prediction as well as in a low molecular mass gel region. All HSP 60 spots had a high relative spot volume. Serine hydroxymethyltransferase appeared on the gel in a lower molecular weight region compared to its theoretical MW, and represented not only the 
highest relative abundance but also the highest relative spot volume. The elongation factor 1alpha was present in-gel in a region of a higher molecular weight than was theoretically expected. As expected, no storage proteins or proteins involved in storage compound metabolism were detected in increased abundance in the somatic embryo proteomes.

\section{Exceptional appearance of enolase}

28 protein spots were identified to be enolase 1 or 2 , representing the largest fraction of all identified spots. Enolase 2 is supposed to be active in the cytosol and enolase 1 in the plastids (Andriotis et al., 2010). However, based on the detected peptides we could not distinguish both isoforms due to their high sequence similarity and leaking enolase sequences for Cyclamen. Thus both isoforms are named "enolase" in our text. These enolase spots were present on 2D gels of both proteomes, and spots covered by at least two peptides were classified into four groups (termed groups A-D in Fig. 3) according to their apparent molecular masses. Only three of the 28 protein spots were localised on the $2 \mathrm{D}$ gels in a molecular mass range in accordance with the calculated molecular mass of enolase (aprox. 50 $\mathrm{kDa}$ ). Twenty three spots had a molecular mass below $50 \mathrm{kDa}$, including a very prominent group of 16 spots that is present in the $16-7 \mathrm{kDa}$ region of the gels. These proteins were classified as the "small group" (group D).

Identified peptides of the three enolases matching the theoretical molecular mass (group B) cover regions between amino acids $100-400$ of the closest related reference sequence, an enolase from Hevea brasiliensis (Q9LEI9). Peptide distribution of group C-enolases (40 kDa) revealed an absence of the motif I (AA 110-125), while group D-enolases located in the 16-7 $\mathrm{kDa}$ gel region comprised the $\mathrm{C}$ - and $\mathrm{N}$-terminal motifs $\mathrm{I}$ and VII/VIII. This specific distribution pattern was also found in the other enolase groups (A-b), but was complemented by additional central motifs. 
Of the 28 enolase spots, nine exhibited significantly higher abundance in the zygotic embryo proteomes ranging from 1.5-4.5 fold, while only three were of higher abundance in the proteomes of somatic embryos (ID641, ID 863, ID 831; 1.5-2.9 fold). Those nine enolase spots of higher abundance in the zygotic embryo proteomes were exclusively present in the “small enolases".

\section{Establishment of a digital proteome reference map}

To establish a digital reference map for zygotic and somatic embryos of Cyclamen persicum, a software named GelMap was developed. This tool, helpful for any gel-based proteomic approach, has been made free and publicly available online on the newly established Cyclamen persicum seed proteome home page. (Figure 4A): http://www.genetik.unihannover.de/cyclamen.html. For our data, the program displays a 2D-gel image of zygotic embryo proteomes (Figure 4B-D). Each of the 247 protein spots identified via MS was marked with a circle and can be clicked on, while spot specific information appears in a popup window including a link to KEGG PATHWAY database for the protein of interest and if available, the protein's EC classification linked to ExPASy Proteomics server (Fig. 4B). By following these links, reactions catalysed by the proteins, their impact on higher metabolic contexts, their amino acid sequence and many more characteristics can be explored. Furthermore, all protein spots involved in one specific physiological process can be viewed separately in the gel by using filter parameters as shown in Figure 4C. The major improvements of this newly developed software tool as compared to previously available programs are the manifold possibilities for filtering data. These parameters can be modified for new reference maps individually. In Figure 4D, filters selecting the identified proteins by source tissue, regulation, protein name and spot ID are shown. All deposited data are accessible online and can be searched interactively for protein names or any conformity. 


\section{Discussion}

In our study, we have characterised more than 1000 protein spots of zygotic and somatic embryos of Cyclamen persicum and have visualised differences between both proteomes using two imaging methods: DIGE (Fig. 2b) and a digitally coloured overlay image of Coomassie stained IEF-SDS PAGEs (Fig. 2a, part C). Mass spectrometry was carried out for protein identifications. Compared to our previous study (Winkelmann et al. 2006) protein resolution was five fold increased from 200 to 1000 protein spots per gel. This was mainly the result of an adapted protein extraction method with a precipitation step and phenol application (Hurkman and Tanaka, 1986) combined with ten times higher tissue input leading to raised protein concentrations and more purified fractions. In addition, MS based protein identification rate could be increased from 24\% (Winkelmann et al., 2006) up to $83 \%$. This was also due to the fact that the number of available sequences in public databases increased. Additionally we have applied quantitative evaluation of two dimensional gels by using the software Delta 2D, while Winkelmann et al. (2006) evaluated gels visually.

By choosing a gel-based approach, we have analysed mostly the soluble proteomes, representing only a part of all proteins present in Cyclamen embryogenic tissues, because most hydrophobic proteins are known to get lost during isoelectric focussing. Furthermore, the molecular mass- and pI-range used for 2-D separation slightly limits the number of proteins detectable. Finally, proteins of low abundance can be assumed to be invisible on our Coomassie-stained gels.

\section{Zygotic and somatic embryo proteomes express significant differences in protein spot}

\section{abundance}

Statistical analyses revealed 246 protein spots of at least 1.5 -fold higher or lower abundance within one of the analysed tissues (Fig. 2a, C), representing $24 \%$ of all spots detected in both tissues. This value is close to the one reported by Winkelmann et al. (2006), who estimated 
that $26 \%$ of proteins were of changed abundance, even though only 200 spots were reproducibly detected and a different Cyclamen genotype and protein extraction method were used in this study. Quantification of relative protein abundance by the DIGE system (Fig. 2b) revealed even higher rates of differentially produced proteins. Indeed, by reducing the confidence interval to $90 \%, 100$ additional spots of altered abundance were also detected on the Coomassie-stained gels (data not shown). Although, we have carefully selected corresponding stages of both embryo types, we can not exclude that those were in slightly different development stages. To elucidate this aspect a time-course based comparative study of somatic and zygotic embryos might be conducted in future studies.

\section{High protein identification rate for the non-model organism Cyclamen was achieved}

Cyclamen represents a non-model organism and has no close relatives within the databases of sequenced plants, hence protein identification was supposed to be challenging. Consequently, Winkelmann et al. (2006) could identify only 25 out of 83 analysed spots, representing an identification rate of $30 \%$. In our current study, the identification rate was increased to $83 \%$. This fact is most likely due to a combination of improved protein purification and gel quality, extension of available protein sequences in public databases and the application of a more sensitive MS-technique. This illustrates that protein identification for non-model plants is becoming more successful. Identification of Cyclamen proteins which are unique to this species or specifically modified may have failed. In this respect, de novo interpretation of mass spectrometry data independently of database information could be helpful in future projects, as described by Höhenwarter et al. (2009).

\section{Glycolysis plays a key role in zygotic and somatic embryogenesis}

$53 \%$ of the non-redundant proteins identified in our study were involved in metabolic processes including carbohydrate metabolism, energy metabolism and other metabolic pathways (see Table S3). This result is comperable to the transcriptomic study published by 
Rensing et al. (2005) on embryogenic callus of Cyclamen persicum. Rensing et al. (2005) showed $69 \%$ of the detected ESTs to be involved in "metabolism" using GO terms. However, the remaining protein classes shown in both datasets are hardly comparable due to different protein annotations used.

Glycolysis represents the most prominent physiological process in both tissues. Since embryogenesis is a developmental process connected with biosynthesis of many compounds, cell division and cell elongation, glycolysis is important for energy supply and formation of several metabolic intermediates like PEP (biosynthesis of fatty acids and aromatic compounds), pyruvate and 3-phospho-D-glycerate (amino acid biosynthesis). Selected enzymes involved in these metabolic pathways were found to be induced in both tissues. The presence of glycolytic enzymes might also allow for the synthesis of carbohydrates via gluconeogenesis in the opposite direction of the glycolytic pathway. However, enzymes specific for glycolysis or gluconeogenesis were not detected in our study. Presumably, both directions of this metabolic pathway are active. Lyngved et al. (2008) found that proteins involved in processing and metabolic processes, including glycolysis, represented the largest classes of proteins found within the proteomes of embryogenic and non-embryogenic calluses of Cyclamen. In accordance, Winkelmann et al. (2006) reported that proteins involved in carbohydrate metabolism are of increased abundance in somatic embryos. It was concluded in both studies that the high abundance of carbohydrate metabolism proteins was most likely evoked by exogenous sucrose. However, in our study, proteins involved in carbohydrate metabolism were of high abundance in zygotic as well as in somatic embryos, a fact which excludes the exogenous sucrose supply as main inducer of glycolytic enzymes. Rather, enzymes of this pathway have a key role in both types of embryogenic tissues. Spots representing the glycolytic enzymes GAPDH, enolase ("normal sized", see below) and malate dehydrogenase were increased in zygotic and in somatic embryos at the same time but 
different in gel positions. This finding indicates the presence of isoforms or posttranslational modifications like phosphorylation, glycosylation or ubiquitination.

\section{Serine/glycine metabolism differs in zygotic and somatic embryos}

Two spots identified as serine hydroxymethyl transferase were highly increased in the somatic embryos. The spot located in the $50 \mathrm{kDa}$ region (ID444, Fig. 2a, part C) was induced 2.6 fold while the spot in the $15 \mathrm{kDa}$ gel region (ID944, Fig. 2a, part C) was 19.9 fold increased. This enzyme catalyses the reversible interconversion of serine and glycine, a central pathway of amino acid metabolism and the major source of one-carbon groups for a variety of pathways (Mattews et al. 1998). Serine is synthesised from 3-phospho-D-glycerate, the product of GAPDH within glycolysis. This enzyme was identified in 20 protein spots, three of which were significantly more abundant in the expected MW area in SE and three others in ZE (see digital reference map), as mentioned before. This is in accordance to Winkelmann et al. (2006) who found three spots corresponding to GAPDH in ZE and SE, but specifically regulated. Lyngved et al. (2008) could identify 7 GAPDH spots, four of which were unique for the embryogenic tissue. Obviously GAPDH is modified differentially in both tissues.

\section{Somatic embryos are more stressed than their zygotic counterparts}

Proteins involved in the stress response were frequently found during the plant embryogenesis, both in vitro and in vivo (e.g., Lippert et al. 2005; Winkelmann et al 2006; Marsoni et al. 2008; for review, see Zavattieri et al. 2010). Although these proteins were found in our study in both proteomes, they were especially abundant in the somatic embryos. Catalases, which are represented by a very prominent spot group in the somatic embryo proteomes on our gels (Fig. 2a, part C), catalyse the decomposition of hydrogen peroxide and have a very high activity (Chelikani et al. 2004). Therefore, they are powerful tools in the detoxification processes. Osmotin-like proteins, such as anti-oxidant 1 and peroxiredoxin II, which were found to be of high abundance in SE, are also involved in reactive oxygen species 
detoxification. A high abundance of these enzymes suggests the occurrence of stress within the somatic embryos tissue beyond that due to embryogenesis. A histological study performed by Hönemann et al. (2010) revealed that somatic embryos of $C$. persicum are surrounded by a particularly stained epidermis, composed of cells with probably cutinised and/or lignified cell walls. Since phenylpropanoid metabolism including lignin synthesis has been reported to be stress-induced (Dixon and Paiva 1995), the enrichment of this cell wall stabilising substance at the outer cell layers is an indicator for an exogenously triggered stress response. In accordance, Hönemann et al. (2010) found genes involved in oxidative stress response to be up-regulated in somatic embryos and consequently suggested the reduction of factors that cause stress during in vitro cultivation.

\section{In zygotic embryos, storage compound pathways are more distinct}

Proteins related to seed development and storage compound accumulation (7S globulin (Fig. 2a, part C), GDSL esterase/lipase and Em like protein (Fig. 2a, part C)), were of higher abundance in ZE. This result is in accordance with the work of Winkelmann et al. (2006), who found $7 \mathrm{~S}$ globulin to be highly induced in ZE. The storage compound $11 \mathrm{~S}$ globulin, found by Winkelmann et al. (2006) to be highly abundant in both types of embryos, was not identified in our current study. However, this possibly could be explained by the fact that $11 \mathrm{~S}$ globulin was isolated from embryos grown on medium containing $60 \mathrm{~g} / \mathrm{l}$ sucrose (Winkelmann et al. 2006). Winkelmann et al. (2006) as well as Klimaszewska et al. (2004) observed a higher accumulation of storage proteins for somatic embryos grown in increased sucrose concentrations, suggesting that these conditions promote storage compound accumulation. The enrichment of storage compounds within SE could be additionally conduced by a maturation-promoting ABA treatment (Finkelstein et al., 2002). Also, insights into the physiological interactions between the endosperm and the developing embryo could help to understand storage compound formation in the zygotic system. This knowledge could 
be helpful for improvement of in vitro conditions for somatic embryogenesis in future approaches.

\section{Enolases play an important role in Cyclamen embryogenesis}

The occurrence of enolases was especially striking in our study. Represented by 28 spots, enolases were some of the most frequently detected proteins and spots, and were observed in a widespread pattern over the gels. Furthermore, peptide coverage for the enolase forms exhibited surprising features (Fig. 3). A highly abundant group of "small enolases" was characteristic for the zygotic embryo proteomes. The main physiological role of enolase is the reversible conversion of 2-phospho-D-glycerate and to phosphoenolpyruvate (PEP) within the glycolytic pathway (Wold and Ballou 1957; Van Der Straeten et al. 1991). PEP not only is important as a substrate for a further glycolytic reaction but also represents a precursor for the biosynthesis of fatty acids (Andriotis et al. 2010). Consequently, enolase has been shown to be highly abundant in high oil sunflower seeds (Hajduch et al. 2007) as well as in fatty acid accumulating Brassica seeds (Hajduch et al. 2006). Additionally, enolase is part of gluconeogenesis and hence is important in starch accumulating seeds like maize (Mechin et al. 2007) or barley (Ostergaard et al. 2004). Since in seeds of Cyclamen starch and fatty acids are utilised as storage compounds (Reinhardt, 2006) and additionally large amounts of PEP are needed for energy supply in developing tissue, high enolase abundance is expected. Coincident to our study, Hajduch et al. (2007) as well as Mechin et al. (2007) found multiple spots of enolase in gels. These were interpreted to represent isoforms or differentially modified forms. However, in contrast to our study, all enolase spots were approximately within the expected MW area. High enolase abundance has not only been found in whole seeds, but also in embryos: Andriotis et al. (2009) analysed transcript abundance of enolase and found maximal amounts for enolase within the torpedo-stage of Arabidopsis embryos. By the analysis of four developmental stages of somatic embryogenesis in Picea, Lippert at al. 
(2005) reported enolase to be one of the most abundant proteins in more maturated stages, suggesting enolase to be a marker in embryogenic maturation.

\section{"Small enolases" exhibit homologies to storage compounds and structure proteins}

The role of "small enolases" (Fig. 2a, part C; Fig. 3, group D) has not been discussed in the above mentioned studies and can not be explained by a catalytic function since an enolase form one-third smaller than theoretically expected is not supposed to be enzymatically active. A proteolytic degeneration of active enolases during purification can not be finally excluded even though protein purification was performed at low temperatures using a buffer containing protease inhibiting EDTA, PMSF and a protease inhibitor cocktail. However, "small enolases" exhibit characteristics suggesting that these spots are not artifacts, but parts of specifically regulated cellular processes: (i) $\mathrm{N}$ - and C-terminal peptides are present in the amino acid sequences of "small enolases" (Fig. 3, group D). Proteolysis should result in forms lacking either the $\mathrm{N}$ - or the $\mathrm{C}$ terminus. (ii) "Small enolases" are of significant higher abundance in the zygotic embryos proteome (Fig. 2a, part $\mathrm{C}$ and 2b). A proteolytic degeneration during protein purification would have affected both tissues equally. (iii) In the study published by Winkelmann et al. (2006) the "small enolases" occurred in the IEF-SDS PAGEs of the proteomes of zygotic embryos, endosperm and somatic embryos cultivated in medium containing $60 \mathrm{~g} / \mathrm{l}$ sucrose. They were missing, if somatic embryos had been cultivated in medium containing $30 \mathrm{~g} / \mathrm{l}$ sucrose (like also applied in this study) and they were no longer detectable in germinated embryos. Thus, the group of "small enolases" exhibits the typical accumulation pattern of storage proteins which are highly abundant in storage tissues like zygotic embryos and endosperm, but are missing in the germinating embryos. Taken together, several arguments are in favour of our hypothesis that enolases serve as storage proteins in Cyclamen persicum. 
A possible biological explanation is the accumulation of "small enolases" in the zygotic embryo proteomes as storage compounds. The small enolases possibly evolved from the 48 $\mathrm{kDa}$ forms but are missing central sequence parts, which include amino acids essential for enolase activity.

In yeast enolase, four amino acids were reported to be of basic relevance for the active site: Glu168, Glu211, Lys345, and Lys369 (Reed et al. 1996; Larsen et al. 1996). Additionally, Ser39 and His159 are involved in major conformation changes in response to substrate binding (Reed et al. 1996). These six amino acids are all conserved in the enolase sequence of $H$. brasiliensis (Q9LEI9) as well as in the one of $V$. vinifera (A7QGT) as revealed by ClustalW analyses (data not shown). However, due to insertions/ deletions of some amino acids, their locations in the respective organisms are slightly different. The corresponding amino acids of yeast and $\underline{H}$. brasiliensis include the following: Ser39 = $\underline{\text { Ser43}}$; His $159=$ His164; Glu168 = Glu173; Glu211 = $\underline{\text { Glu216; }}$ Lys345 = Lys353; Lys396 = Lys404. Three of the six conserved amino acids (His164, Glu216 and Lys353) were covered by peptides identified by MS (Fig. 3). All three amino acids are covered by peptides in the class-B enolase group. Additionally, His 164 and Glu216 were present in the $39 \mathrm{kDa}$ class-C enolase group. In all other enolase groups, only Lys353 was present (Fig. 3). Thus, the active site residues His 164 and Glu173 are absent in the "small enolases" (Fig. 3).

Reed et al. (1996) showed that mutation of one of the four main active site AA residues reduced enolase activity $10^{4}-10^{5}$ fold. Molecular background for the deletion of sequence stretches within enolase could be due to gene rearrangement, alternative splicing (Van der Straeten et al. (1991) reported 12 or more introns for plant enolase genes), transsplicing, or protein splicing. Comparable properties have been reported for common seed storage proteins like prolamins, 7S globulins, $11 \mathrm{~S}$ globulins and albumins, which function exclusively as storage compounds but are structurally and phylogenetically related to enzymes (Shewry 
1995). A more multifunctional occurrence of storage proteins, comparable to the one discussed for enolase, was shown for potato tubers storage proteins (for review see Shewry 2003). Patatin from potato is involved in lipid metabolism (Galliard 1971; Hirschberg et al. 2001) and plant defence (Matos et al. 2000, 2001), sporamin from sweet potato functions as a trypsin inhibitor (Yeh et al. 1997) and dioscorin from yam represents a carbonic anhydrase (Hou et al. 1999). One interesting link between patatin and enolase can be found in the study of Höhenwarter et al. (2008). Here, proteomes of six potato tuber cultivars were analysed and patatin specific peptides were found to be highly abundant in five of them, but in one cultivar, enolase specific peptides were highly abundant suggesting probable substitution of patatin as a storage compound in this special cultivar.

Structural proteins are a further group of enzymatically inactive or poorly active proteins which can accumulate highly in specific tissues. Wistow et al. (1988) found $\tau$-crystalin (a structural component in the eye lens of vertebrates) and enolase to be encoded by the same or by a closely related gene, suggesting that the resulting proteins are also closely related. Wistow et al. (1988) assumed a gene duplication or gene inversion event within the ancestor enolase gene or at the protein level, gene-sharing or function-specific posttranslational modifications of enolase. Consistently, the activity of enolases from eye lens has been shown to be significantly lower $(0.045-3.3 \mathrm{U} / \mathrm{mg})$ as compared with the one measured in commercial enolase from rabbit muscles (35 - $90 \mathrm{U} / \mathrm{mg}$ ) (Wistow et al. 1988). Regarding this background, a structural function of a modified enolase, like the "small enolase" in Cyclamen, seems probable.

In conclusion, enolases which are needed in the first stages of embryogenesis and seed formation might be inactivated and "recycled" in form of storage proteins. To elucidate the specific role of "small enolases" in Cyclamen embryo cells, an immunohistological approach would give essential information pertaining to functional arrangement. Additionally, amino 
acid sequence determination by Edman-degeneration of "small" and normal-sized enolases as well as analyses by electron microscopy could be helpful for further characterisation of the various enolase forms present in Cyclamen embryos. Last but not least, sequencing of enolase genes or cDNAs will give insights into the molecular biology of this group of proteins.

\section{Proteomic reference map displays data for 247 protein spots}

The identity and physiological clustering of the 247 most abundant protein spots within the ZE and SE proteomes of C. persicum are published on our publicly available digital reference map (Figure $4 \mathrm{~A}$ and $\mathrm{B}$ ). This platform is intended to support future studies on the development and maturation of somatic and zygotic Cyclamen embryos. To get a more defined idea of metabolic pathways within these tissues, additional MS analyses for the identification of low abundant spots as well as analyses of further seed tissues are ongoing in our laboratory. 


\section{Acknowledgments}

The authors would like to thank Michael Senkler for programming GelMap and for computerrelated assistance, Kathrin Lindhorst for her excellent technical assistance in the lab, Dr. Frank Colditz and Jenniffer W. Mwangi for critically reading the manuscript and Varinova for providing Cyclamen plants. The project was funded by the DFG (Deutsche Forschungsgemeinschaft-German Research Foundation). 


\section{References}

Andriotis VM, Kruger NJ, Pike MJ, Smith AM (2010) Plastidial glycolysis in developing Arabidopsis embryos. New Phytol 185:649-62

Bian F, Zheng C, Qu F, Gong X, You C (2010) Proteomic Analysis of Somatic Embryogenesis in Cyclamen persicum Mill. Plant Mol Biol Rep 28:22-31

Chelikania P, Fitab I, Loewen PC (2004) Diversity of structures and properties among catalases. Cell Mol Life Sci 61:192-208

Colditz F, Nyamsuren O, Niehaus H, Eubel H, Braun HP, Krajinski F (2004) Proteomic approach: Identification of Medicago truncatula proteins induced in roots after infection with the pathogenic oomycete Aphanomyces euteiches. Plant Mol Biol 55:109-120

Damerval C, De Vienne D, Zivy M, Thiellement H (1986) Technical improvements in twodimensional electrophoresis increase the level of genetic variation detected in wheat-seedling proteins. Electrophoresis 7:52-54

Dixon RA, Paiva NL (1995) Stress-Induced Phenylpropanoid Metabolism. Plant Cell 7:10851097

Finkelstein RR, Gampala, SSL, Rock CD (2002) Abscisic Acid Signaling in Seeds and Seedlings. Plant Cell 14:15-45

Fuehrs H, Goetze S, Specht A, Erban A, Gallien S, Heintz D, Van Dorsselaer A, Kopka J, Braun HP, Horst WJ (2009) Characterization of leaf apoplasticperoxidases and metabolites in Vigna unguiculata in response to toxic manganese supply and silicon. J Exp Bot 60:16631678

Galliard T (1971) The enzymic deacylation of phospholipids and galactolipids in plants: purification and properties of a lipolytic acyl-hydrolase from potato tubers. Biochem $\mathrm{J}$ $121: 379-390$

Hajduch M, Casteel JE, Hurrelmeyer KE, Song Z, Agrawal GK, Thelen, JJ (2006) Proteomic Analysis of Seed Filling in Brassica napus. Developmental Characterization of Metabolic Isozymes Using High-Resolution Two-Dimensional Gel Electrophoresis. Plant Physiol $141: 32-46$

Hajduch M, Casteel JE, Tang S, Hearne LB, Knapp S, Thelen JJ (2007) Proteomic Analysis of Near-Isogenic Sunflower Varieties Differing in Seed Oil Traits. J Prot Res 6:3232-3241

Hajduch M, Ganapathy A, Stein JW, Thelen JJ (2005) A systematic proteomic study of seedfilling in soybean: establishment of high-resolution two-dimensional reference maps, expression profiles, and an interactive proteome database. Plant Physiol 137:1397-1419. 
Hirschberg HJHB, Simons JWFA, Dekker N, Egmond MA (2001) Cloning, expression, purification and characterization of patatin, a novel phospholipase A. Eur J Biochem 268:5037-5044.

Hoenemann C, Richardt S, Krüger K, Zimmer AD, Hohe A, Rensing SA (2010) Large impact of the apoplast on somatic embryogenesis in Cyclamen persicum offers possibilities for improved developmental control in vitro. BioMed Cent Plant Biol 10:77. doi:10.1186/14712229-10-77

Hoehenwarter W, Van Dongen JT, Wienkoop S, Steinfath M, Hummel J, Erban A, Sulpice R, Regierer B, Kopka1 J, Geigenberger P, Weckwerth, W (2008) A rapid approach for phenotype-screening and database independent detection of cSNP/protein polymorphism using mass accuracy precursor alignment. Proteomics 8:4214-4225

Hou WC, Liu JS, Chen HJ, Chen TE, Chang CF, Lin YH (1999) Dioscorin, the major tuber storage protein of yam (Dioscorea batatas Decne) with carbonic anhydrase and trypsin inhibitor activities. J Agricult Food Chem 47:2168-2172

Hurkman WJ, Tanaka CK (1986) Solubilization of plant membrane proteins for analysis by two-dimensional gel electrophoresis. Plant Physiol 81:802-806

Kiviharju E, Tuominen U, Tormala T (1992) The effect of explant material on somatic embryogenesis of Cyclamen persicum Mill. Plant Cell Tiss Org Cult 28:187-194

Klimaszewska K, Morency F, Jones-Overton C, Cooke J (2004) Accumulation pattern and identification of seed sorage proteins in zygotic embryos of Pinus strobus and in somatic embryos from different maturation treatments. Physiol Plant 121:682-690

Larsen, T. M., Wedekind, J. E., Rayment, I., and Reed, G. H. A (1996) Carboxylate Oxygen of the Substrate Bridges the Magnesium Ions at the Active Site of Enolase: Structure of the Yeast Enzyme Complexed with the Equilibrium Mixture of 2 Phosphoglycerate and Phosphoenolpyruvate at 1.8 Å Resolution. Biochem 35:4349-4358

Larsen MR, Fey SJ, Roepstorff P (2001) Characterization of differently processed forms of enolase 2 from Saccharomyces cerevisiae by two-dimensional gel electrophoresis and mass spectrometry. Electrophoresis 22:566-575

Lippert D, Zhuang J, Ralph S, Ellis DE, Gilbert M, Olafson R, Ritland K, Ellis B, Douglas CJ Bohlman J (2005) Proteome analysis of early somatic embryogenesis in Picea glauca. Proteomics 5:461-473

Lyngved R, Renaut J, Hausman JF, Iversen TH, Hvoslef-Eide AK (2008) Embryo-specific proteins in Cyclamen persicum analysed with 2-D DIGE. J Plant Growth Regul 27:353-369

Malinowski R, Filipecki M (2002) The role cell wall in plant embryogenesis. Cell Mol Biol Let 7:1137-1151 
Marsoni M, Bracale M, Espen L, Prinsi B, Negri AS, Vannini V (2008) Proteomic analysis of somatic embryogenesis in Vitis vinifera. Plant Cell Rep 27:347-356

Matthews RG, Drummond JT, Webb HK (1998) Cobalamin-dependent methionine synthase and serine hydroxymethyltransferase. Targets for chemotherapeutic intervention? Adv Enz Regul 38:377-392

Matos AR, d'Arcy-Lameta A, Franca M, Zuily-Fodil Y, Pham-Thi AT (2000) A patatin-like protein with galactolipase activity is induced by drought stress in Vigna unguiculata leaves. Biochem Soc Transact 28:779-781

Matos AR, d'Arcy-Lameta A, França M, Petres S, Edelman L, Kader JC, Zuily-Fodil Y, Pham-Thi AT (2001) A novel patatin-like gene stimulated by drought stress encodes a galactolipid acyl hydrolase. Fed Eur Biochem Soc Let 491:188-192

Mechin V, Thevenot C, Le Guilloux M, Prioul JL, Damerval C (2007) Developmental analysis of maize endosperm proteome suggests a pivotal role for pyruvate orthophosphate dikinase. Plant Physiol 143:1203-1219

Murashige T, Skoog F (1962) A revised medium for rapid growth and bioassays with tobacco tissue cultures. Physiol Plant 15:473-497

Ostergaard O, Finnie C, Laugesen S, Roepstorff P, Svensson B (2004) Proteome analysis of barley seeds: Identification of major proteins from two-dimensional gels ( $\mathrm{p} I$ 4-7). Proteomics $4: 2437-2447$

Prange ANS, Serek M, Bartsch M, Winkelmann T (2010) Efficient and stable regeneration from protoplasts of Cyclamen coum Miller via somatic embryogenesis. Plant Cell Tiss Org Cult 101:171-182

Prange ANS, Bartsch M, Serek M, Winkelmann T (2010) Regeneration of different Cyclamen species via somatic embryogenesis from callus, suspension cultures and protoplasts. Sci Hort $125: 442-450$

Reinert J (1959) Morphogenese und ihre Kontrolle an Gewebekulturen aus Carotten. Naturwissenschaften 45:344-345

Reed G H, Poyner RR, Larsen TM, Wedekind JE, Rayment I (1996) Structural and mechanistic studies of enolase. Curr Opin Struct Biol 6:736-743

Reinhardt S (2006) Vergleichende morphologische-anatomische und physiologische Untersuchung zur Samenanlagenqualitaet von Cyclamen persicum Mill.: unterbesonderer Beruecksichtigung der Saatgutqualitaet. Dissertation, Friedrich-Schiller-University Jena, Germany

Rose JKC, Bashir S, Giovannoni JJ, Jahn MM, Saravanan RS (2004) Tackling the plant proteome: practical approaches, hurdles and experimental tools. Plant J 39:715-733 
Schwenkel HG, Winkelmann T (1998) Plant regeneration via somatic embryogenesis from ovules of Cyclamen persicum Mill. Plant Tiss Cult Biotech 4:28-34

Shewry PR (1995) Plant storage proteins. Biol Rev 70:375-426

Shewry PR (2003) Tuber storage proteins. Ann Bot 91:755-769

Steward FC, Mapes MO, Smith J (1958) Growth and organized development of cultured cells. I. Growth and division of freely suspended cells. Am J Bot 45:693-703

Van Der Straeten D, Rodriguespousada RA, Goodman HM, Van Montagu M (1991) Plant enolase-gene structure, expression, and evolution. Plant Cell 3:719-735

Willekens H, Chamnongpol S, Davey M, Schraudner M, Langebartels C,Van Montagu M, Inzé D, Van Camp W (1997) Catalase is a sink for $\mathrm{H}_{2} \mathrm{O}_{2}$ and is indispensable for stress defence in C3 plants. Eur Mol Biol Org J 16:4806-4816

Wicart G, Mouras A, Lutz A (1984) Histological study of organogenesis and embryogenesis in Cyclamen persicum tissue cultures: evidence for a single organogenetic pattern. Protoplasma 119:159-167

Winkelmann T, Hohe A, Schwenkel HG (1998) Establishing embryogenic suspension cultures in Cyclamen persicum 'Purple Flamed'. Adv Hort Sci 12:25-30

Winkelmann T, Serek M (2005) Genotypic differences in callus formation and regeneration of somatic embryos in Cyclamen persicum Mill. Euphytica 144:109-116

Winkelmann T, Heintz D, Van Dorsselaer A, Serek M, Braun HP (2006) Proteomic analyses of somatic and zygotic embryos of Cyclamen persicum Mill. reveal new insights into seed and germination physiology. Planta 224:508-519

Wistow GJ, Lietman T, Williams LA, Stapel SO, De Jong WW, Horwitz J, Piatigorsky J (1988) Tau-crystallin/alpha-enolase: One gene encodes both an enzyme and a lens structural protein. J Cell Biol 107:2729-2736

Wold F, Ballou CE (1957) Studies on the enzyme enolase. J. Biol. Chem. 227, 301-328

Yeh, K.-W., Lin, M. L., Tuan, S. J., Chen, Y.-M., Lin, C.Y., Kao, S.S. 1997. Sweet potato (Ipomoea batatas) trypsin inhibitors expressed in transgenic tobacco plants confer resistance against Spodoptera litura. Plant Cell Rep 16:696-699

Zavattieri MA, Frederico AM, Lima M, Sabino R, Arnoldt-Schmitt B (2010) Induction of somatic embryogenesis as an example of stress-related plant reactions. Electron $\mathrm{J}$ Biotechnol 13. doi: 10.2225/vol13-issue1-fulltext-4

Zimmerman JL (1993) Somatic embryogenesis: a model for early development in higher plants. Plant Cell 5:1411-1423 

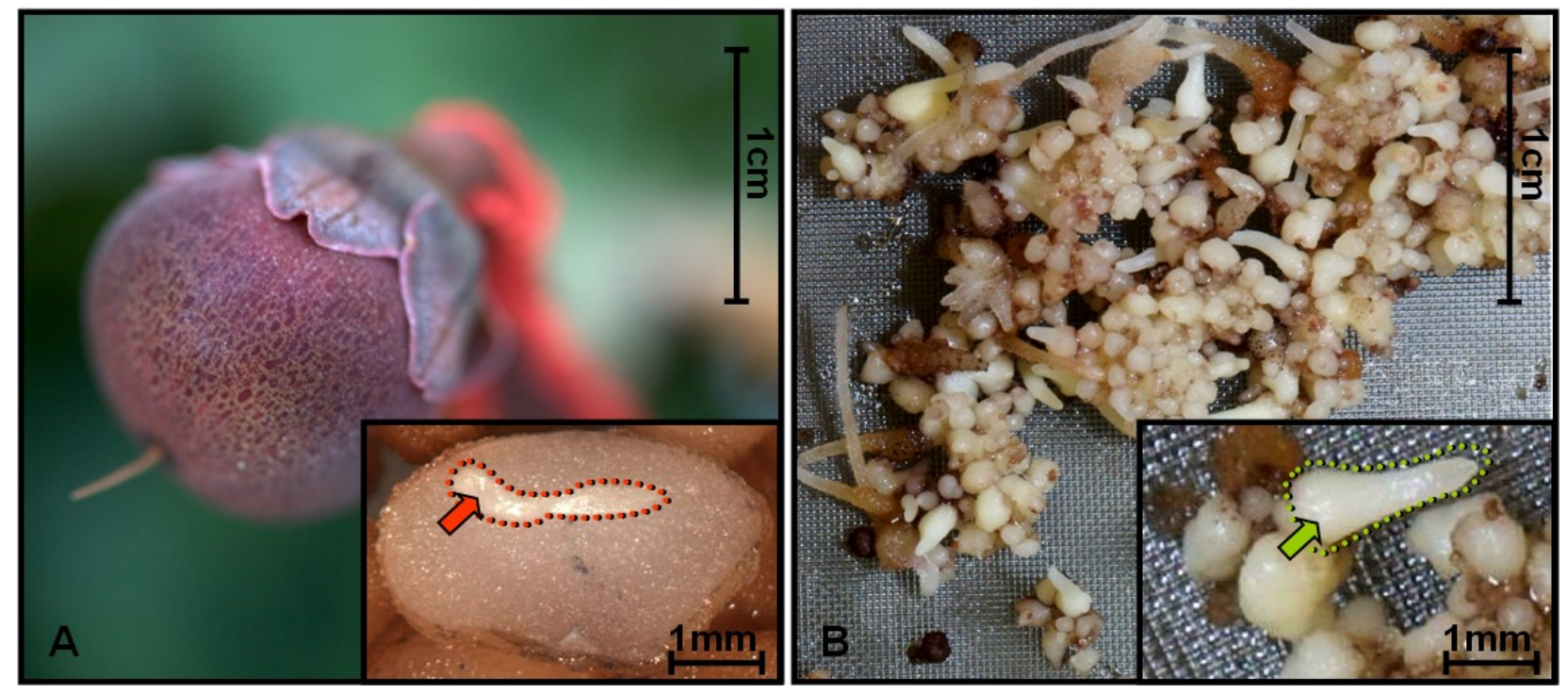

Figure 1 Zygotic and somatic embryos of Cyclamen persicum

A: 11-week-old fruit. Detail: Longitudinal section of one seed. Torpedo-shaped zygotic embryo (labelled with a red arrow) embedded in endosperm.

B: Somatic embryos after four weeks of differentiation on solid, hormone free medium. Detail: torpedo-shaped somatic embryo (labelled with a green arrow). 


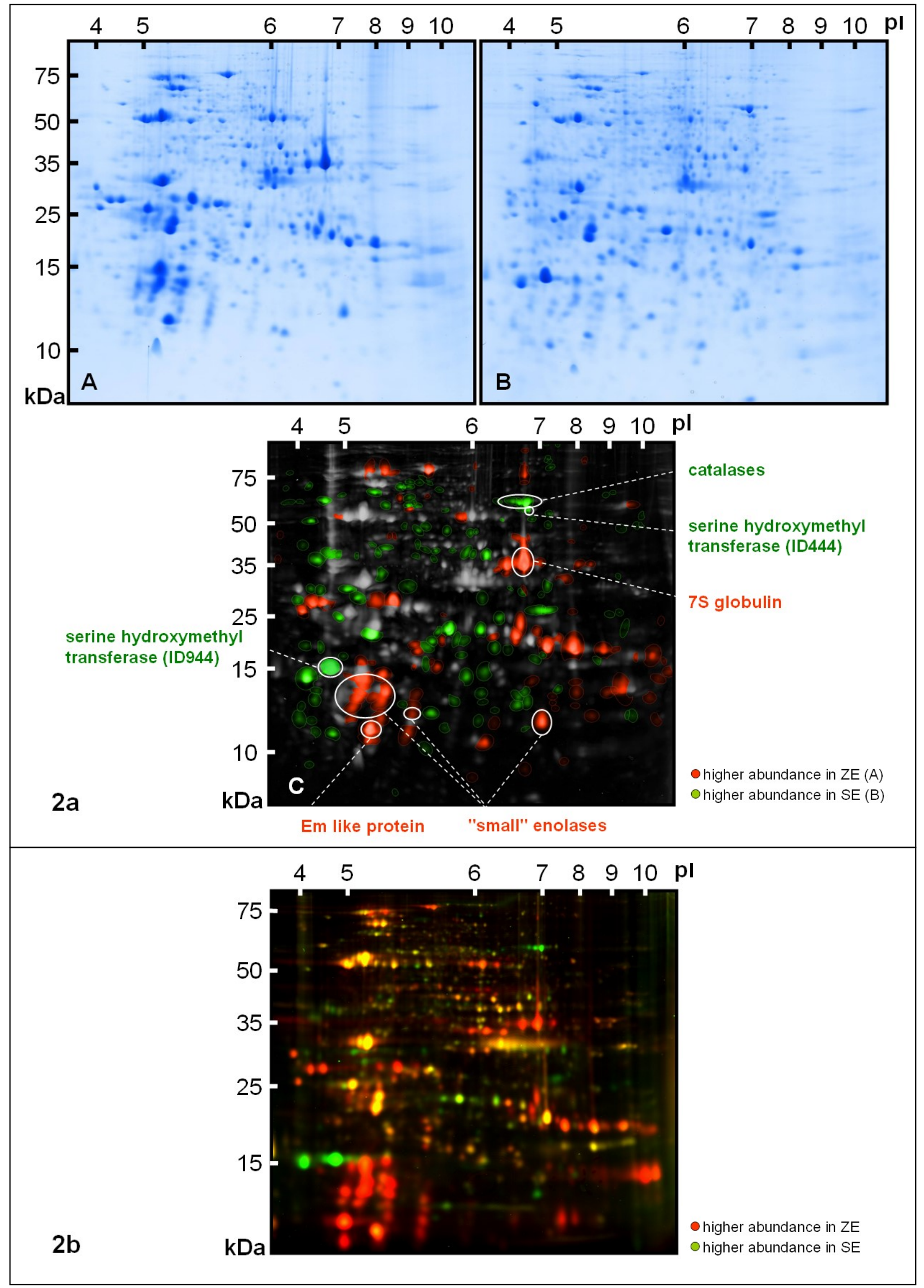


Figure 2 Alterations in protein abundance of protein spot pattern in the proteomes of the somatic and zygotic embryos

2a: IEF-SDS PAGE of total soluble protein fractions extracted from $80 \mathrm{mg}$ fresh embryo tissue. Gels were stained with CBB-G 250.

A: Zygotic embryos.

B: Somatic Embryos. Molecular mass range: 100-5 kDa (top to bottom). Non-linear separation: pI 3-11 (left to right).

C: Overlay image of IEF-SDS PAGE of zygotic and somatic embryo proteomes (four replicates) using Delta2D software. Red-labelled spots were at least 1.5 -fold more abundant in the zygotic embryo proteomes and green-labelled spots were at least 1.5-fold more abundant in the somatic embryo proteomes. Spots of major interest discussed in detail in the text are indicated.

2b: IEF-SDS DIGE overlay image of zygotic and somatic embryo proteomes. The zygotic protein fraction was labelled with $\mathrm{Cy} 3$ (red), the somatic protein fraction with Cy5 (green). Spots with similar abundance in both tissues appeared yellow. 

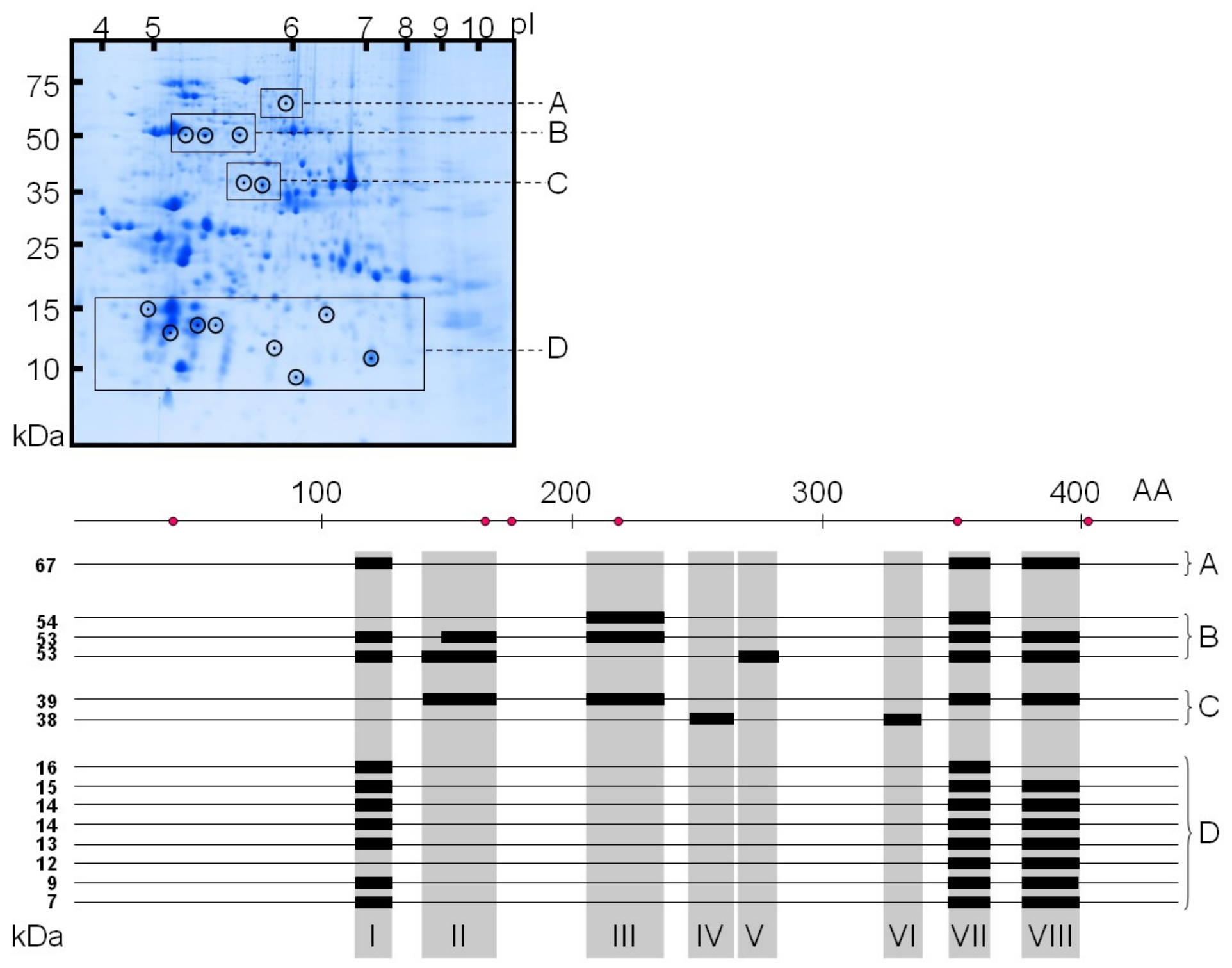

Figure 3 Alignment of identified peptides matching to enolase sequences in $C$. persicum

Each line represents one enolase sequence of Hevea brasiliensis (Q9LEI9, $47.91 \mathrm{kDa}, 445$ AA). The sequences are sorted by the approximated molecular weight of the corresponding spots on the gel which is shown in the upper part of the figure. Spots of comparable size appeared in four groups: A: $70 \mathrm{kDa}$ group, B: $50 \mathrm{kDa}$ group, C: $40 \mathrm{kDa}$ group, D: small group $(16-7 \mathrm{kDa})$. Black bars indicate peptides of the enolase sequence identified via mass spectrometry in the spot of the corresponding size. Only sequences covered by at least two peptides are shown. The 8 unique peptide motives are labelled with black boxes and numbered I-VIII. Pink dots at the top of the figure are indicating the five amino acids involved in the active site of enolase (left to right: Ser43, His164, His173, Glu216, Lys353, Lys404). 

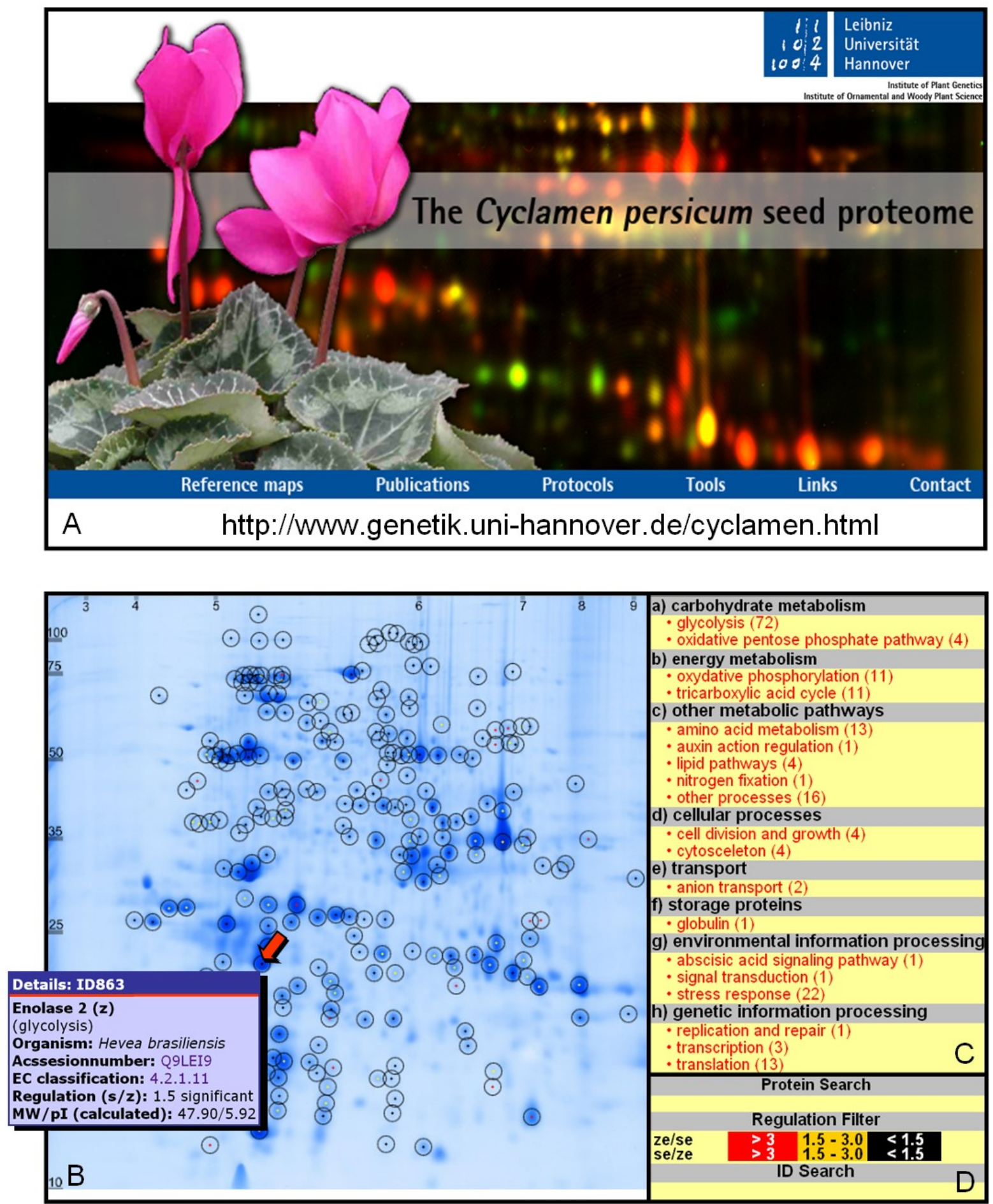

Figure 4 Digital reference map of the Cyclamen persicum embryo proteome

A: Screen shot of the Cyclamen persicum seed proteome home page. By clicking on the button "Reference maps" the user is forwarded to the reference map shown below. B: IEFSDS PAGE of zygotic embryo total protein fractions is shown. Spots labelled with a black circle were successfully identified using mass spectrometry. By clicking on each labelled spot, specific spot information appears in a pop-up window. C: Filters selecting identified proteins by their physiological function. D: Filters selecting identified proteins by their source, regulation, protein name and spot ID. For creating the digital reference map, in-house developed GelMap software was used and can be downloaded from the web page mentioned above. 


\begin{tabular}{|c|c|c|c|c|}
\hline Protein $^{1}$ & Function $^{2}$ & Abundance $^{3}$ & Spot volume ${ }^{4}$ & Spot ID ${ }^{5}$ \\
\hline Oxidoreductase & other processes & 5.3 & 0.1 & ID655 \\
\hline Succinate/malate CoA ligase & tricarboxylic acid cycle & 3.6 & 0.1 & ID700 \\
\hline Malate dehydrogenase & glycolysis/glyconeogenesis & 3.4 & 1.4 & ID702, ID648, ID637 \\
\hline Voltage-dependent anion channel & anion transport & 3.2 & 0.2 & ID886 \\
\hline Copper/zinc superoxide dismutase & stress response & 2.8 & 0.5 & ID767 \\
\hline Ubiquitin & protein modification & 2.6 & 0.8 & ID810 \\
\hline 6-phosphogluconate dehydrogenase & oxidative pentose phosphate pathway & 2.4 & 0.2 & ID476 \\
\hline Heat shock protein 20 & protein folding & 2.3 & 1.8 & ID911, ID898, ID880, ID879, ID16827 \\
\hline Thioredoxin peroxidase 1 & stress response & 1.9 & 0.7 & ID961 \\
\hline Universal stress protein & stress response & 1.9 & 0.2 & ID881 \\
\hline Actin 1 & cytoskeleton & 1.8 & 0.3 & ID472 \\
\hline Cysteine desulfurase & amino acid metabolism & 1.5 & 0.2 & ID952 \\
\hline Auxin-amidohydrolase & auxin action regulation & 4.8 & 0.4 & ID853 \\
\hline GDSL esterase/lipase & lipid pathways & 2.7 & 0.3 & ID9002 \\
\hline Em-like protein & embryogenesis/seed germination & 2.5 & 1.1 & ID1059 \\
\hline $7 S$ globulin & storage proteins & 2.3 & 2.2 & ID8764 \\
\hline Phosphoglycerate kinase & glycolysis/glyconeogenesis & 2.2 & 0.7 & ID998, ID9067 \\
\hline Thiosulfate sulfurtransferase & other processes & 2.0 & 0.2 & ID884 \\
\hline Universal stress protein & stress response & 1.6 & 0.3 & ID9796 \\
\hline Monodehydroascorbate reductase & other processes & 1.5 & 0.1 & ID473 \\
\hline
\end{tabular}

$\square \mathrm{MW}$ in gel according to theoretical MW

$\square \mathrm{MW}$ in gel lower than theoretical MW

Table 1b Proteins of increased abundance in the somatic embryo proteomes

\begin{tabular}{|c|c|c|c|c|}
\hline \multicolumn{5}{|c|}{ Proteins of increased abundance in the somatic embryos proteome } \\
\hline Protein $^{1}$ & \begin{tabular}{|r|} 
Function $^{2}$ \\
\end{tabular} & Abundance $^{3}$ & Spot volume $^{4}$ & Spot ID ${ }^{5}$ \\
\hline $\begin{array}{l}\text { Osmotin-like protein } \\
\text { Anti-Oxidant } 1 \\
\text { Peroxiredoxin type II } \\
\text { Catalase } \\
\text { Nucleoside diphosphate kinase } \\
\text { 2-oxoacid dehydrogenase } \\
\text { Serine hydroxymethyltransferase } \\
\text { Eukaryotic translation initiation factor } \\
\text { Eukaryotic initiation factor } 4 \mathrm{~A} \\
\text { Aldehyde dehydrogenase } \\
\text { Glutamine synthetase } \\
\text { Aminopeptidase } \\
\text { LEA family protein } \\
\text { Heat shock protein } 60 \\
\text { putative uncharacterized protein }\end{array}$ & $\begin{array}{l}\text { stress response } \\
\text { stress response } \\
\text { stress response } \\
\text { stress response } \\
\text { other processes } \\
\text { tricarboxylic acid cycle } \\
\text { amino acid metabolism } \\
\text { translation } \\
\text { translation } \\
\text { glycolysis/glyconeogenesis } \\
\text { nitrogen fixation } \\
\text { protein degradation } \\
\text { embryogenesis/seed germination } \\
\text { protein folding } \\
\text { uncharacterized }\end{array}$ & $\begin{array}{l}12.9 \\
10.6 \\
7.7 \\
6.0 \\
6.0 \\
4.9 \\
2.6 \\
2.6 \\
2.6 \\
2.6 \\
2.6 \\
2.0 \\
2.0 \\
1.9 \\
1.8\end{array}$ & $\begin{array}{l}0.5 \\
0.5 \\
0.2 \\
1.1 \\
0.4 \\
0.1 \\
0.1 \\
1.0 \\
1.0 \\
0.1 \\
0.2 \\
0.1 \\
0.2 \\
0.4 \\
0.1 \\
\end{array}$ & \begin{tabular}{|l} 
ID3770, ID791 \\
ID1074 \\
ID17171 \\
ID386, ID388, ID392 \\
ID1001, ID1024 \\
ID519 \\
ID444 \\
ID830 \\
ID1887 \\
ID387 \\
ID597 \\
ID413 \\
ID621 \\
ID355 \\
ID1014 \\
\end{tabular} \\
\hline $\begin{array}{l}\text { Serine hydroxymethyltransferase } \\
\text { Heat shock protein } 60\end{array}$ & $\begin{array}{l}\text { amino acid metabolism } \\
\text { protein folding }\end{array}$ & $\begin{array}{c}19.9 \\
7.3 \\
\end{array}$ & $\begin{array}{l}2.7 \\
1.5 \\
\end{array}$ & \begin{tabular}{|l|} 
ID944 \\
ID9070 \\
\end{tabular} \\
\hline Elongation factor 1-alpha & translation & 1.8 & 0.1 & ID959 \\
\hline
\end{tabular}

$\square M W$ in gel according to theoretical MW $\square$ MW in gel lower than theoretical MW $\quad \square$ MW in gel higher than theoretical MW

${ }^{1}$ Proteins identified in the current study. Protein name according to the best hit of MASCOT search against TAIR9, GreenPlant and NCBI databases. Detailed information on mass spectrometry parameters for each spot analysed is given in supplementary material (Table S2).

2 functional protein classification according to KEGG PATHWAY Database. Additionally embryogenesis specific grouping was added.

${ }^{3}$ protein spot abundance: Statistically significant values of at least 1.5 fold more abundant protein spots are given for the zygotic (relative spot volume ZE/relative spot volume SE) and somatic (relative spot volume $\mathrm{SE} /$ relative spot volume $\mathrm{ZE}$ ) embryos proteomes. According to the colour-coding in Figure $2 \mathrm{a}$, part $\mathrm{C}$ and $2 \mathrm{~b}$, protein spots of increased abundance in the zygotic embryos proteome are labelled red, while protein spots of increased abundance in the somatic embryos proteome are labelled green.

${ }^{4}$ relative spot volume based on area and intensity relatively obtained in each gel. For different spots of comparable size identified as the same protein, the relative spot volumes were summed for each gel and the mean of the summed relative spot volumes is shown.

${ }^{5}$ spot ID represents the unique number of a protein spot in the 2D PAGEs. Corresponding spots of all 8 gels are labelled with the same ID. 